\title{
THE INFLUENCE OF INCRUSTATION AND CHUTE BLOCKAGE ON THE DYNAMIC BEHAVIOUR OF A BUCKET WHEEL EXCAVATOR SLEWING SUPERSTRUCTURE
}

\author{
Nebojša B. Gnjatović, SrĐan M. Bošnjak, Ivan L.J. Milenović \\ University of Belgrade, Faculty of Mechanical Engineering, Belgrade, Serbia \\ e-mail:ngnjatovic@mas.bg.ac.rs; sbosnjak@mas.bg.ac.rs; imilenovic@mas.bg.ac.rs
}

\begin{abstract}
Exploitation of bucket wheel excavators (BWEs) is accompanied by an increase of mass due to transport and adherence of a large amount of the material. Technical regulations do not account for the dynamic behaviour of BWEs. Such problems are analysed as quasi-static. A procedure and results of investigation of the influence of masses of the bucket wheel (BW) incrustation and soil in a blocked BW chute on the superstructure response are presented. Analysis of sensitivity of dynamic characteristics and the response to adherence of the material is conducted. The method and results can be used in the design stages of new and in reconstructions of obsolete BWEs.
\end{abstract}

Keywords: bucket wheel excavator, dynamic behaviour, adhered material, vibrations

\section{Introduction}

Bucket wheel excavators (BWEs) are high capacity machines operating in extremely harsh working conditions under the influence of loads of a pronounced dynamic nature. Experimentally and analytically obtained results of analysis of the dynamic behaviour serve as a foundation of modern methods for calculating structural stability (Cireş and Nani, 2016), as well as fatigue (Pietrusiak et al., 2017; Rusiński et al., 2017) and reliability (Karray et al., 2017; Ognjanović and Benur, 2011; Ognjanović et al., 2014) of bearing substructures and power transmission systems of BWEs. The approach to analysis of the dynamic behaviour of BWEs should be of a holistic nature, since analysis of individual subassemblies with disregard of their interaction with the rest of the dynamic system could lead to results which may not correspond to the actual behaviour of the construction (Schlecht, 2014). Variation of operational parameters over a continuous domain (Bartelmus and Zimroz, 2009; Bošnjak et al., 2015; Huss, 2014) should also be included in order to simulate conditions of exploitation with sufficient accuracy.

Due to their high capacity, of up to 240000 bank cubic metres per day (Schlecht, 2014), a relatively high influence of the soil material is present during exploitation of the analysed class of machines. A part of the excavated material is transported along the machine, while some of it adheres to the elements of the working device, conveyors, chutes and the bearing structure. The adherence of the soil material to the elements of the working device (buckets) and the conveying system leads to a decrease in capacity, i.e. technological failures, as described in (Bošnjak and Zrnić, 2012). Furthermore, it also leads to an increase in loading of the machine structure. Congestions of transport system transfer points (bucket wheel chute and chutes of the conveying system) may also result in machine overload and jeopardise its static stability, strength and dynamic behaviour.

The influence of the soil material on the BWE strength and static stability in the design phase is thoroughly covered by the current technical regulations. The Standards (AS4324.1, 1995; DIN 22261-2, 2016), by whose recommendations the majority of BWEs operating in the 
world were designed, account for incrustation of the bucket wheel and conveyors, incrustation of buckets (which is included when determining the digging force, and is stated not to be treated separately) and the appearance of chute blockages. Although the maximum masses of the soil material on the machine, when accounted for, ensure that strength and stability calculations will be on the side of safety, it is not guaranteed that the dynamic response of the BWE structure will be on the side of safety as well.

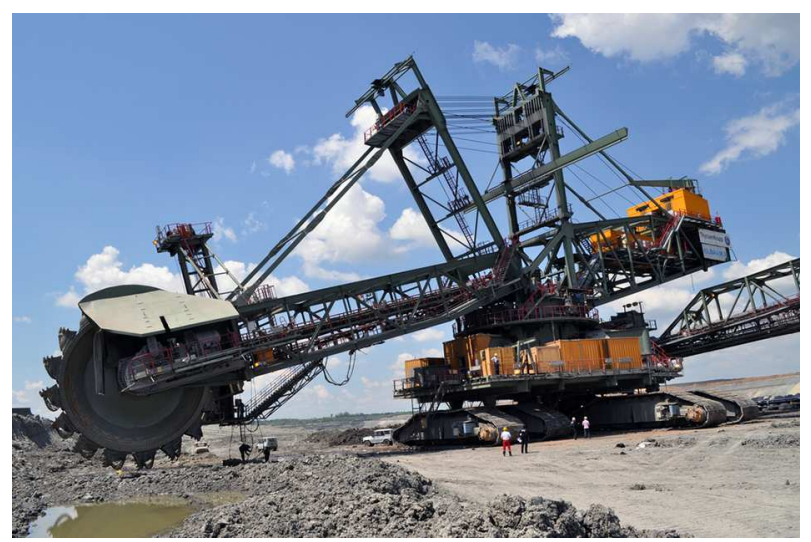

Fig. 1. BWE SchRs 1600 in operating conditions (mass 3345 t, theoretical capacity $6600 \mathrm{~m}^{3} / \mathrm{h}$

(Schneider, 2007))

The object of investigations presented in this paper is the BWE SchRs 1600 slewing superstructure, Fig. 1. Calculated according to Standard (DIN 22261-2, 2016), mass of the bucket wheel $(\mathrm{BW})$ incrustation for the analysed BWE is $m_{B W I}=20 \mathrm{t}$, while mass of the material in the completely blocked BW chute is $m_{B W C}=61 \mathrm{t}$ (Schneider, 2007). In relation to the mass of the BW (BW body +17 buckets) $m_{B W}=68 \mathrm{t}$ (Schneider, 2007) $m_{B W I}$ and $m_{B W C}$ are equal to $29.4 \%$ and $89.7 \%$, respectively. These were the primary motives to present the procedure and results of the investigation of the influence of masses of the BW incrustation and soil in the blocked BW chute (the so-called 'adhered material') on the dynamic response of the BWE slewing superstructure in this paper. The importance of the presented investigations stems from the following facts: (1) in the field of BWE dynamics (Bošković et al., 2015; Bošnjak et al., 2015; Rusiński et al., 2012, 2017; Volkov and Cherkasov, 1969) the problem of influence of the BW incrustation as well as the BW chute blockage is not analysed (considered) in the referent literature; (2) the method and obtained results have a wider application because they can be used both in the design stages of new BWEs as well as in reconstructions of BWs of obsolete design solutions, with the goal of a more appropriate adaptation of the machines to operating conditions, as well as improving maintenance procedures; (3) the presented analysis procedures may be successfully applied for similar machines such as bucket wheel reclaimers.

\section{Dynamic model}

The analyses of modal characteristics and the dynamic response of the BWE SchRs 1600 superstructure were conducted on the basis of a spatial (3D) discrete dynamic model with 64 DOF, Fig. 2. The depicted model, developed and validated according to the procedures presented in (Bošnjak et al., 2006; Gnjatović, 2016), enables modal analysis as well as analysis of the dynamic response in a continuous domain of the considered parameter variation. In principle, a change in the geometric configuration of the slewing superstructure, i.e. variation of the BW boom inclination angle leads to variation in the values of its natural frequencies (Bošnjak and Gnjatović, 2016; Gottvald, 2012). If modal characteristics of the model with the horizontal position of the 


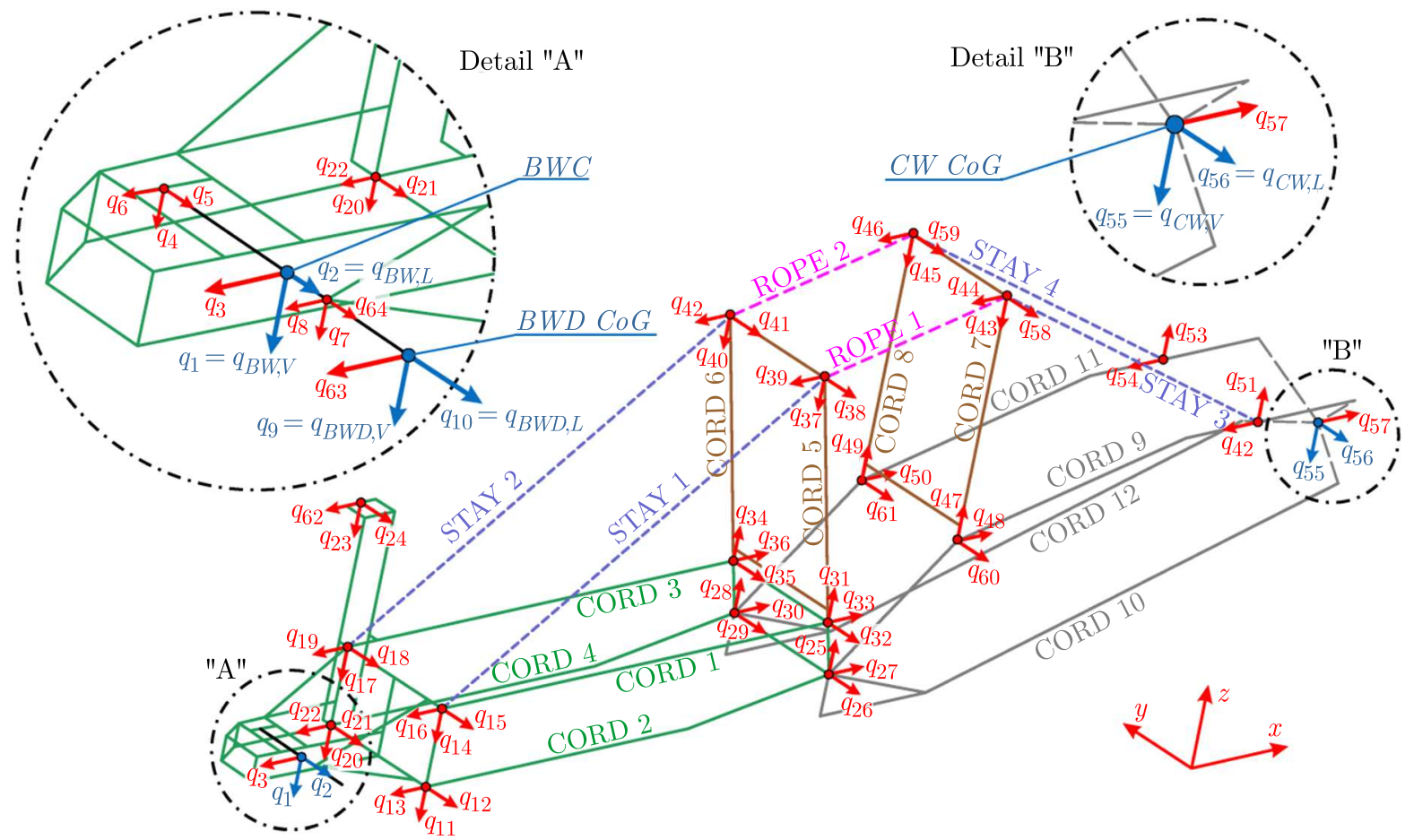

Fig. 2. A 3D discrete dynamic model of the BWE SchRs 1600 slewing superstructure: $q_{B W, V}=q_{1}, q_{B W, L}=q_{2}$ - vertical and lateral displacements of the BW centre; $q_{B W D, V}=q_{9}, q_{B W D, L}=q_{10}$ - vertical and lateral displacements of the BW drive gearbox CoG; $q_{C W, V}=q_{55}, q_{C W, L}=q_{56}-$ vertical and lateral displacements of the $\mathrm{CW} \mathrm{CoG}$

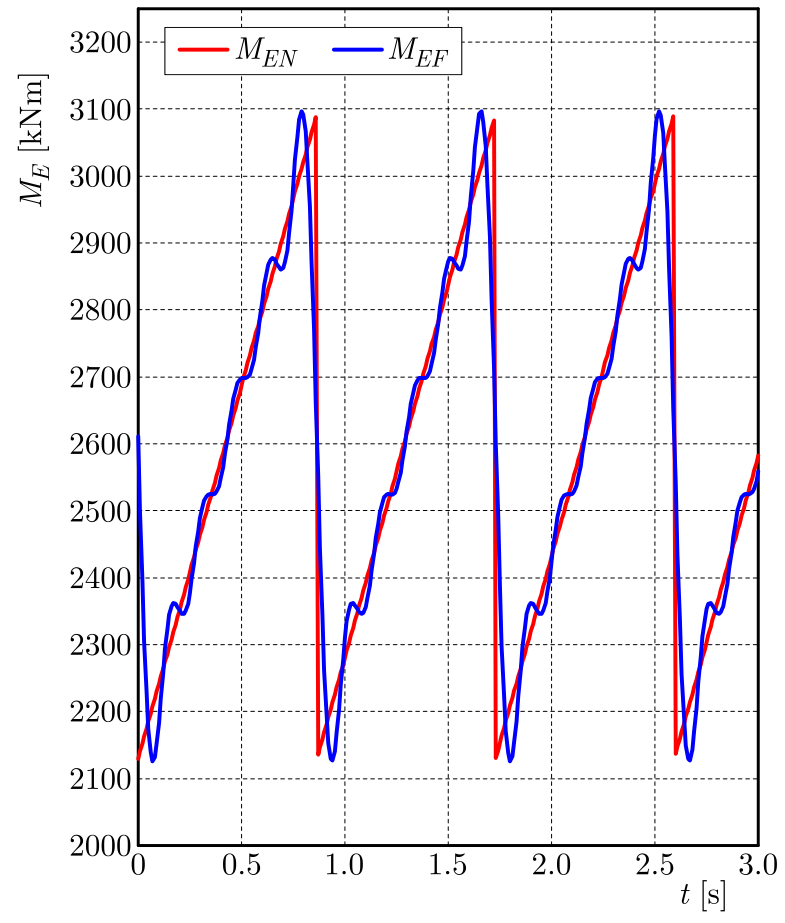

Fig. 3. Nominal moment of the excavation curve $\left(M_{E N}\right)$ and its approximation via Fourier series $\left(M_{E F}\right)$

BW boom are adopted as the basis for comparison, then the biggest difference is obtained for the fifth natural mode, for the BW boom inclination angle of $-19.5^{\circ}$ (Gnjatović, 2016). The absolute value of the percentage difference for the described slewing superstructure configuration is $3.3 \%$. For this reason, modal characteristics of the slewing superstructure model with the 
horizontal position of the BW boom were adopted as referent for further analysis. Identification of the external load caused by the resistance to excavation, Fig. 3, was conducted using the procedure presented in (Arsić et al., 2011; Bošnjak et al., 2009). The forced response of the model was determined by applying Lagrange's second order equations, which are commonly used to analyse the behaviour of complex dynamic systems (Brusa et al., 2014; Cireş and Nani, 2016; Volkov and Cherkasov, 1969), on the assumption that the structural damping may be neglected in the out-of-resonance region, (Bošnjak et al., 2015).

According to previous investigations (Bošnjak and Zrnić, 2012; Bošnjak et al., 2015; Gnjatović, 2016), published experimental data (Brkić et al., 2014; Gottvald, 2010; Pietrusiak, 2017; Rusiński et al., 2015) as well as Standards (AS4324.1, 1995; DIN 22261-2, 2016), it can be concluded that of all the referent points of the BWE superstructure, used to describe its dynamic behaviour, Fig. 2, the bucket wheel centre (BWC - a point of intersection of the BW vertical plane of symmetry across the buckets and the axis of the bucket wheel shaft) and the centres of gravity (CoGs) of the BW drive gearbox (BWD) and the counterweight (CW) are the most sensitive to variation of the parameters which dominantly influence the dynamic response of the superstructure. The reason for this is twofold: (a) these referent points are treated as carriers of the dominant lumped masses and (b) these points are the most distant from the superstructure support - a slew bearing. For the reasons listed, the presented analyses were conducted for vertical and lateral displacements and accelerations of the aforementioned referent points. Axial displacements and accelerations (along the $x$ axis, Fig. 2) of the referent points were not analysed since the axial stiffnesses of spatial truss structures of the BW and CW booms are significantly higher than their bending and torsional stiffnesses.

\section{Dynamic behaviour of the superstructure in the case of BW incrustation and BW chute blockage}

Although the calculation load case HZS4.4 ('Blocked chutes'), according to (DIN 22261-2, 2016) and the load case III/6 ('Blocked chutes and hoppers') prescribed by (AS4324.1, 1995), consider combined influences of the BW incrustation and the BW chute blockage, they are unlikely to occur simultaneously. Additionally, the maximum weight of the material in the BW chute is limited by the maximum set intensity of the force in ropes of the BW boom hoisting mechanism, which leads to activation of the protection system and a halt in the excavation process. For this reason, mass of the material in the BW chute which leads to a halt in the excavation process is always somewhat lower than the maximum mass of the material determined by the volume of the BW chute. However, in order to fully examine the influence of the material in the BW chute on the natural frequencies and the dynamic response of the slewing superstructure, its mass in the model $\left(\kappa m_{B W C}\right)$ has been varied within the range between $m_{B W C, \min }=0$ (empty BW chute, $\kappa=0)$ and $m_{B W C, \max }=m_{B W C}=61 t$, which corresponds to the case of a completely blocked BW chute (completely filled volume of the BW chute, $\kappa=1$ ). For the purpose of presented analyses, the influences of the BW incrustation and the BW chute blockage were accounted for by including the 'adhered material' as lumped masses $m_{B W I}$ and $\kappa m_{B W C}, 0 \leqslant \kappa \leqslant 1$, into the BWC, Figs. 4-7, Tables 1-3.

Table 1. Influence of the 'adhered material' on the spectrum of natural frequencies

\begin{tabular}{|c|c|c|c|c|c|c|c|c|c|c|c|c|c|}
\hline \multirow{2}{*}{$\kappa$} & \multicolumn{10}{|c|}{ Natural frequency $[\mathrm{Hz}]$} \\
\cline { 2 - 14 } & $f_{1}$ & $f_{2}$ & $f_{3}$ & $f_{4}$ & $f_{5}$ & $f_{6}$ & $f_{7}$ & $f_{8}$ & $f_{9}$ & $f_{10}$ & $f_{11}$ & $f_{12}$ & $f_{13}$ \\
\hline \hline 0 & 0.71 & 0.87 & 0.98 & 1.56 & 1.85 & 2.59 & 2.95 & 3.04 & 3.25 & 3.73 & 4.76 & 5.24 & 6.04 \\
\hline 1 & 0.66 & 0.81 & 0.94 & 1.55 & 1.80 & 2.56 & 2.95 & 3.04 & 3.25 & 3.69 & 4.71 & 5.09 & 5.92 \\
\hline
\end{tabular}


(a)

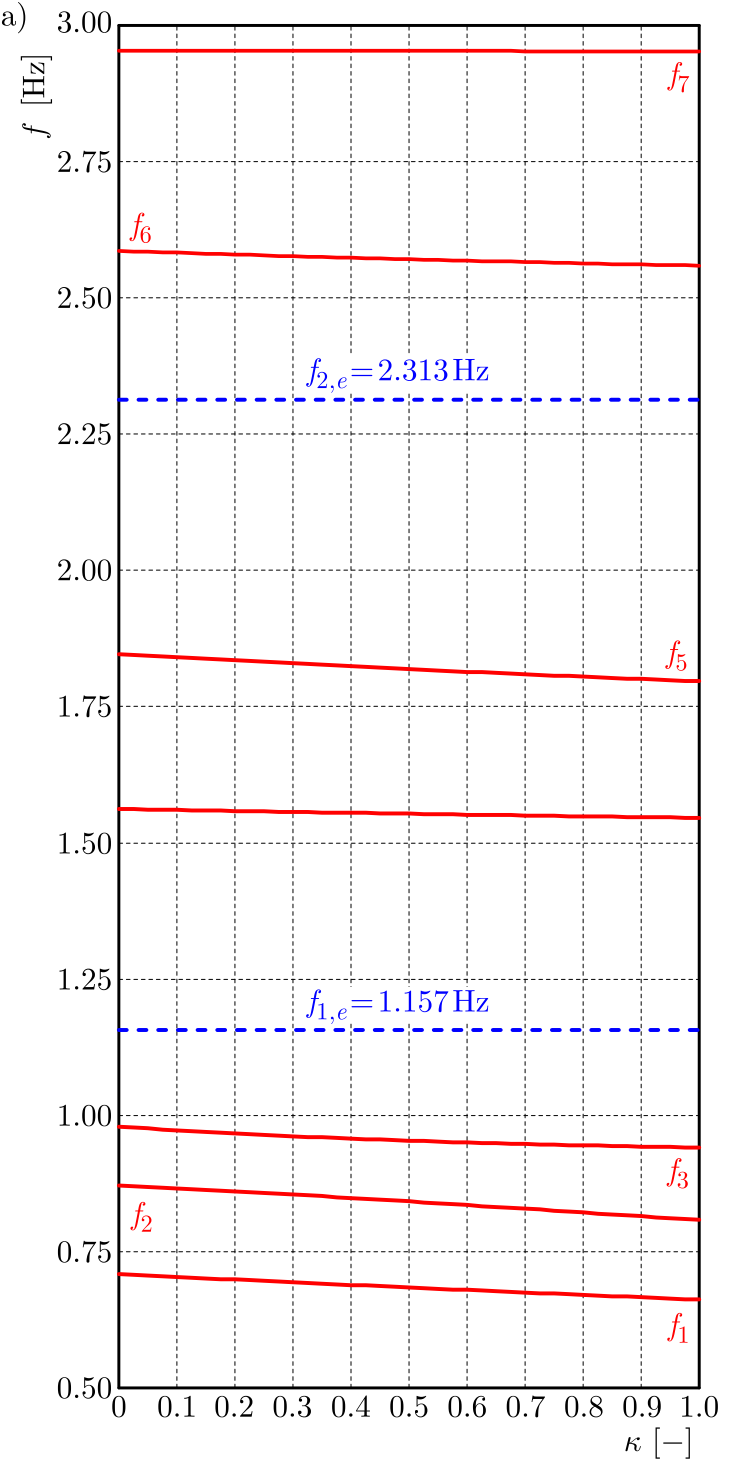

(b)

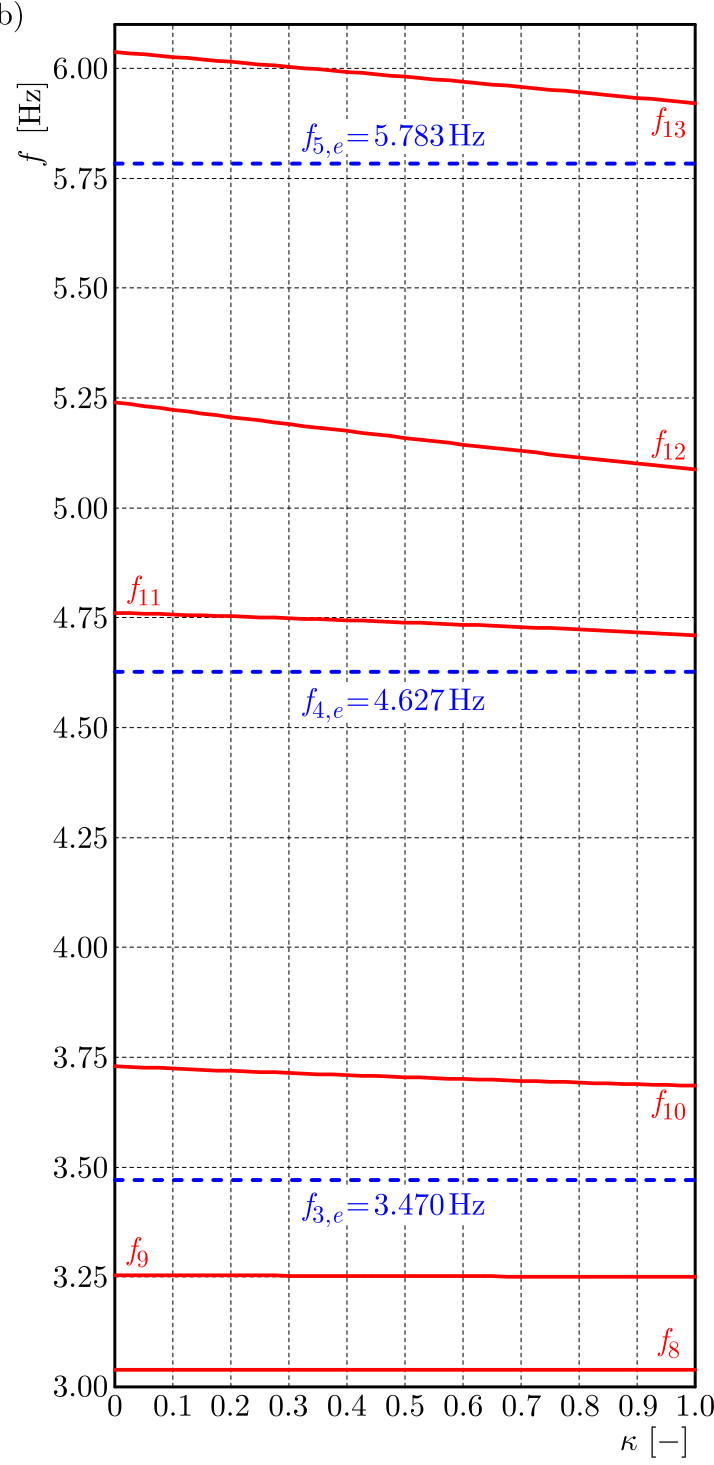

Fig. 4. The first 13 natural frequencies of the slewing superstructure model (solid red lines) vs. frequencies of the first five harmonics of excitation caused by resistance to excavation (dashed blue lines): (a) frequency spectrum 0.5 to $3 \mathrm{~Hz}$, (b) frequency spectrum 3 to $6.1 \mathrm{~Hz}$

Table 2. Maximum/minimum values of displacements for $\kappa=0$ and $\kappa=1$

\begin{tabular}{|l|c|c|}
\hline \multirow{2}{*}{ Displacement } & \multicolumn{2}{|c|}{ Maximum/minimum values $[\mathrm{mm}]$} \\
\cline { 2 - 3 } & $\kappa=0$ & $\kappa=1$ \\
\hline \hline$q_{B W, V, \max }$ & 38.9 & 38.4 \\
\hline$q_{B W, L, \max }$ & 5.1 & 5.5 \\
\hline$q_{B W D, V, \max }$ & 51.7 & 51.8 \\
\hline$q_{B W D, L, \max }$ & 4.5 & 4.9 \\
\hline$q_{C W, V, \min }$ & -8.6 & -9.2 \\
\hline$q_{C W, L, \min }$ & -0.8 & -0.7 \\
\hline
\end{tabular}




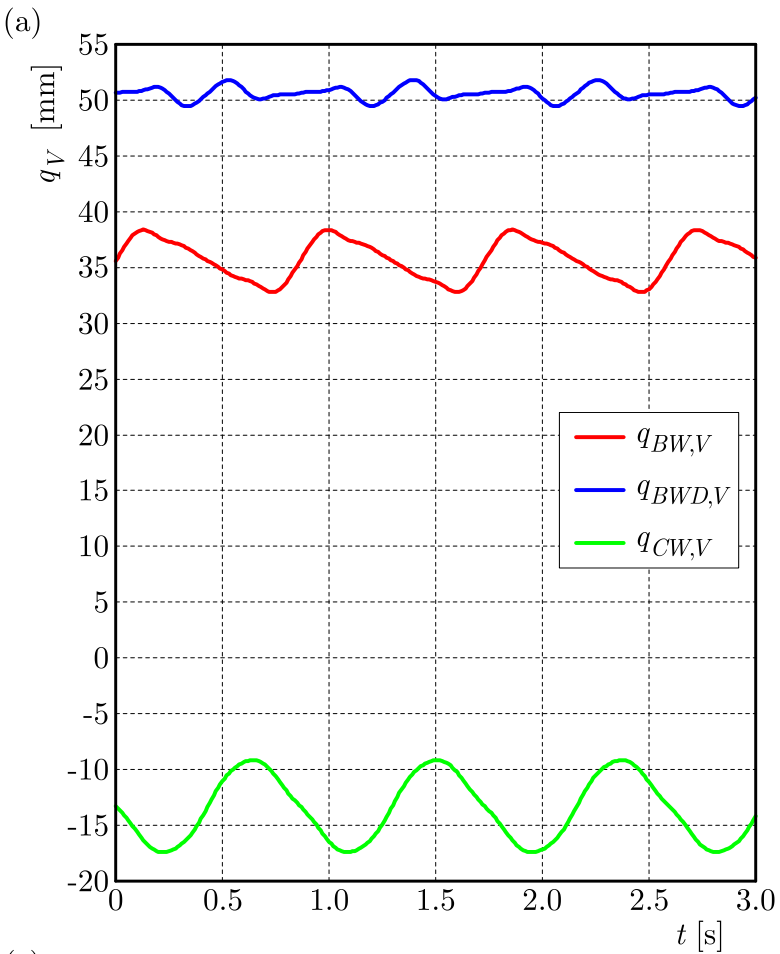

(c)

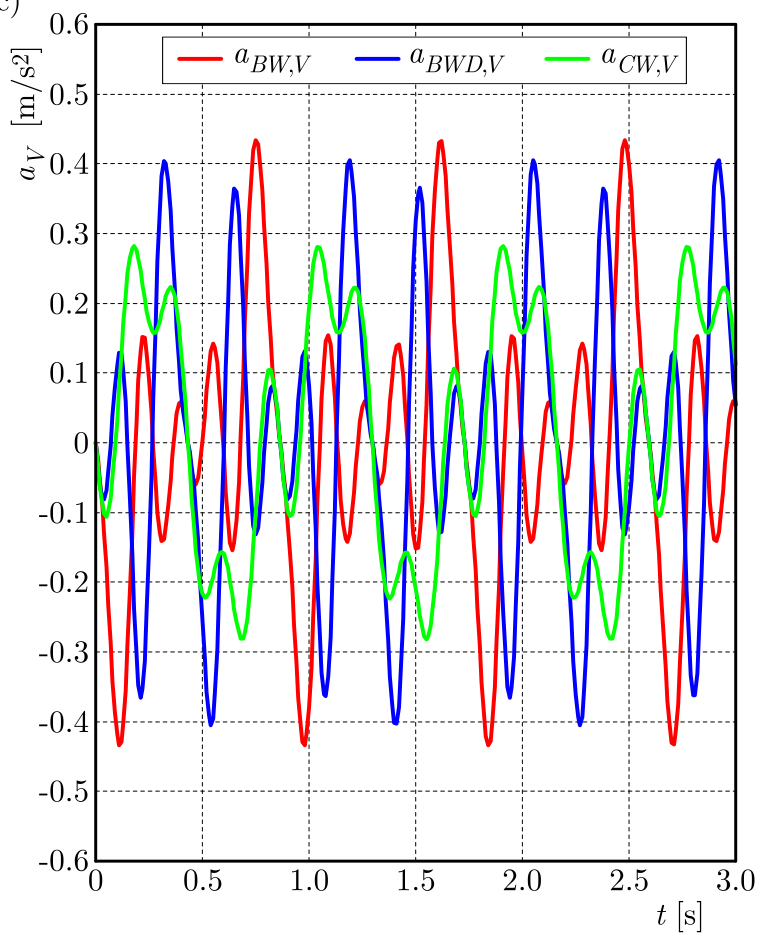

(b)

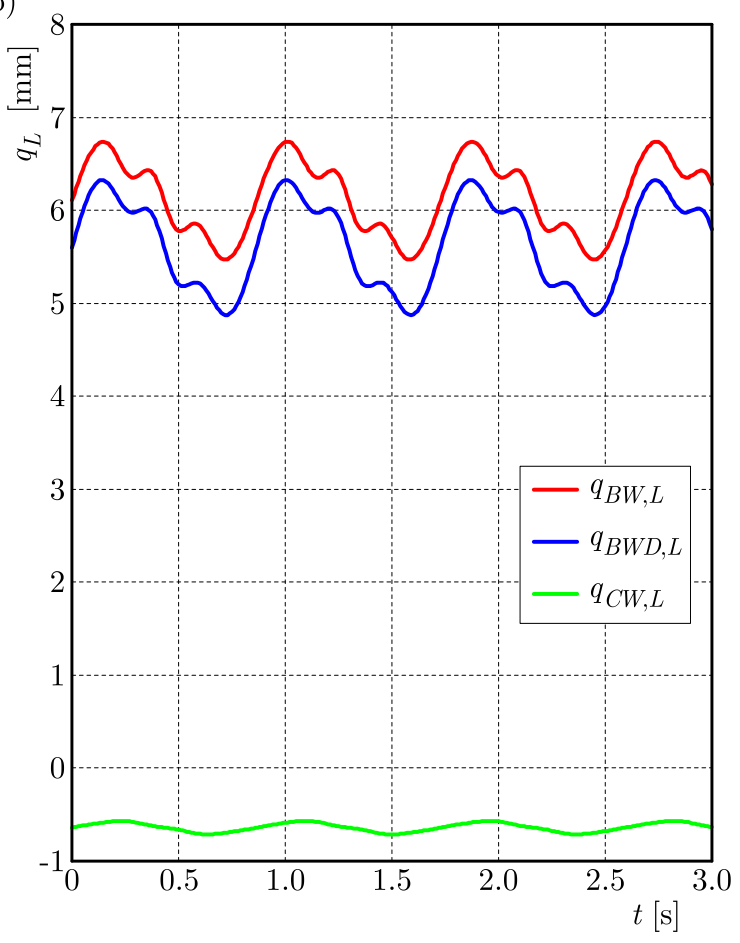

(d)

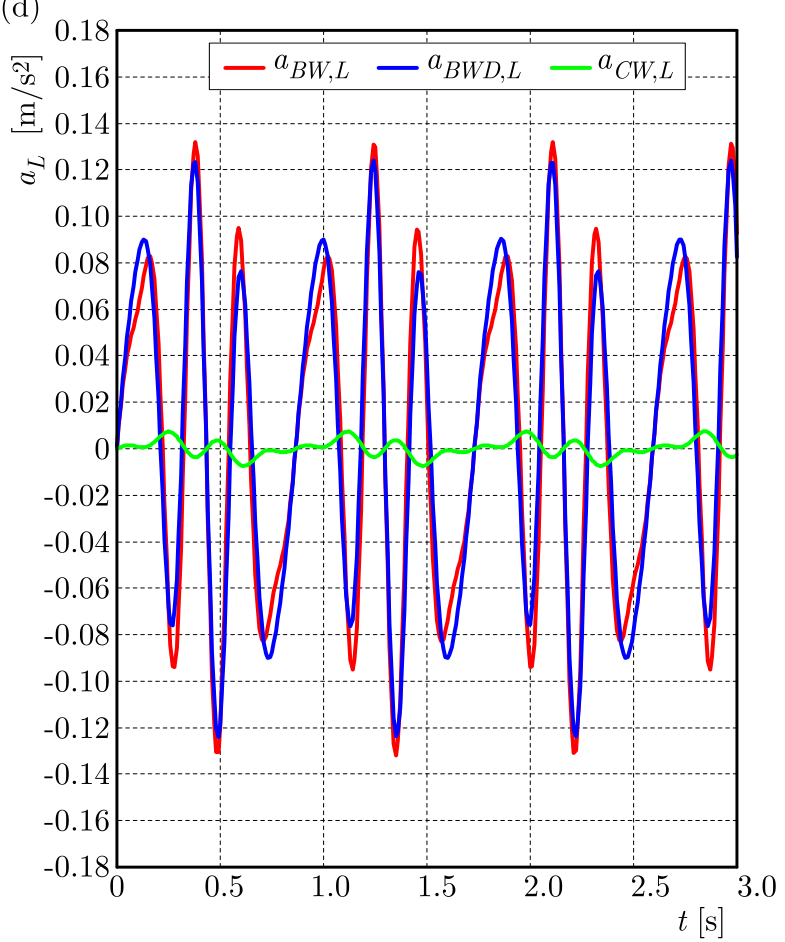

Fig. 5. Dynamic response of the slewing superstructure referent points for $\kappa=1$ : (a) vertical displacements, (b) lateral displacements, (c) vertical accelerations, (d) lateral accelerations

Table 3. Maximum values of accelerations for $\kappa=0$ and $\kappa=1$

\begin{tabular}{|l|c|c||l|c|c|}
\hline \multirow{2}{*}{ Acceleration } & \multicolumn{2}{|c||}{ Maximum value $\left[\mathrm{m} / \mathrm{s}^{2}\right]$} & \multirow{2}{*}{ Acceleration } & \multicolumn{2}{c|}{ Maximum value $\left[\mathrm{m} / \mathrm{s}^{2}\right]$} \\
\cline { 2 - 3 } & $\kappa=0$ & $\kappa=1$ & & $\kappa=0$ & $\kappa=1$ \\
\hline \hline$a_{B W, V, \max }$ & 0.47 & 0.43 & $a_{B W D, L, \max }$ & 0.13 & 0.12 \\
\hline$a_{B W, L, \max }$ & 0.12 & 0.13 & $a_{C W, V, \max }$ & 0.27 & 0.28 \\
\hline$a_{B W D, V, \max }$ & 0.37 & 0.41 & $a_{C W, L, \max }$ & 0.009 & 0.007 \\
\hline
\end{tabular}


(a)

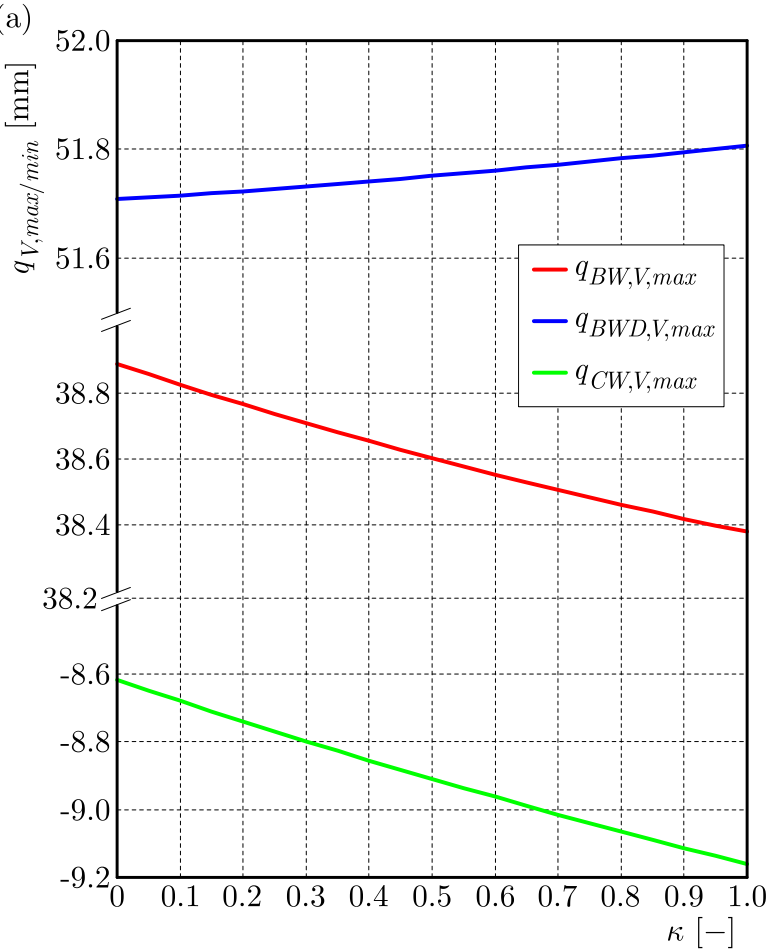

(b)

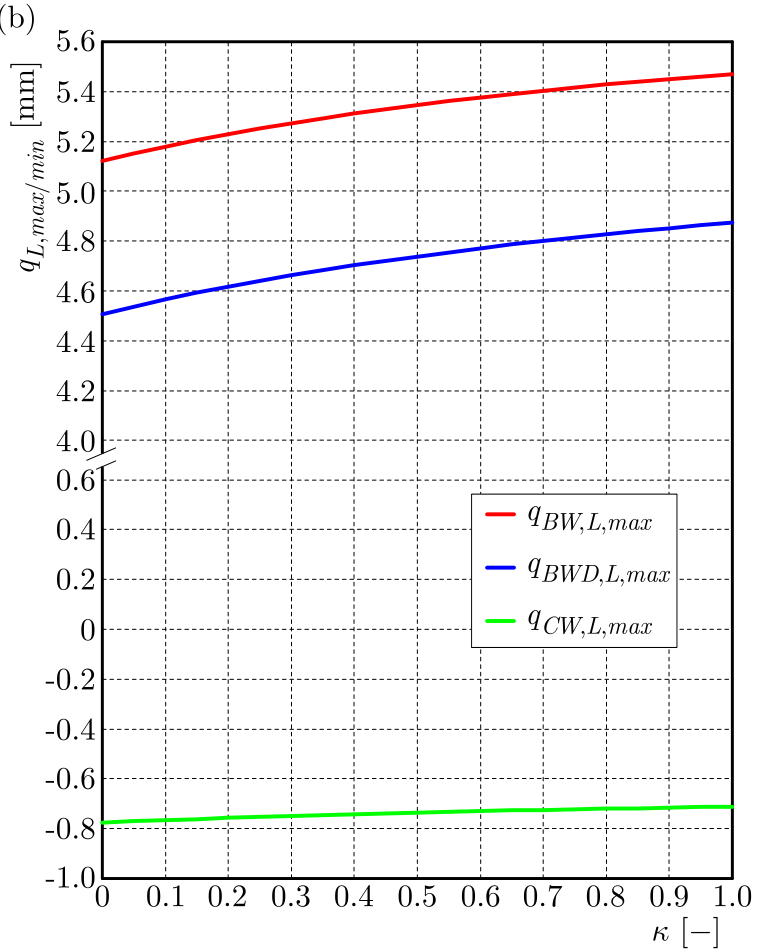

Fig. 6. Maximum/minimum values of (a) vertical and (b) lateral displacements
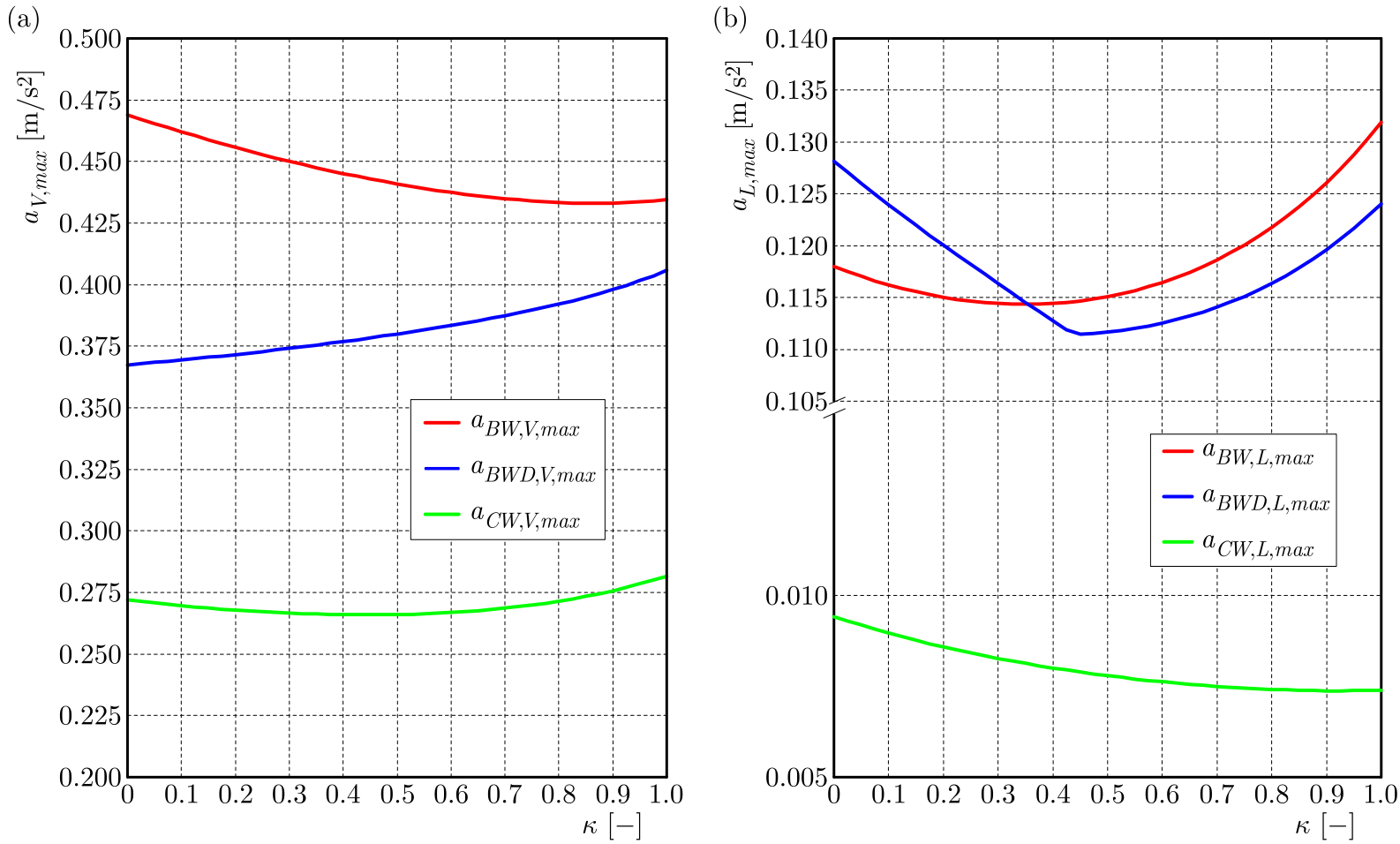

Fig. 7. Maximum values of (a) vertical and (b) lateral accelerations

\section{Discussion}

The curves of natural frequencies versus mass of the 'adhered material' are of a monotonically decreasing character, Fig. 4, Table 1, which was an expected outcome considering the overall increase of the model mass. The first, second and third natural frequencies are the most sensitive to variation of the 'adhered material' mass $(-7 \%,-6.9 \%$ and $-4.1 \%$, respectively), Table 4 . 
The analysed influence, when other natural frequencies are considered, is lower than $3 \%$. At the adopted level of calculation accuracy, it is observed that the seventh through ninth natural frequencies are practically insensitive to variation of the 'adhered material' mass.

Table 4. Percentage decrease in values of the natural frequencies provoked by the soil material adherence

\begin{tabular}{|c|c|c|c|c|c|c|c|c|c|c|c|c|c|}
\hline \multirow{3}{*}{$\begin{array}{l}\text { Percentage } \\
\text { difference }\end{array}$} & \multicolumn{13}{|c|}{ Natural frequency } \\
\hline & \multicolumn{13}{|c|}{$n$} \\
\hline & 1 & 2 & 3 & 4 & 5 & 6 & 7 & \begin{tabular}{|l|l}
8 & 5 \\
\end{tabular} & & 10 & 11 & 12 & 13 \\
\hline$\overline{\bar{A}}$ & $2-7.0$ & -6.9 & -4.1 & -0.6 & -2.7 & -1.2 & 0 & \begin{tabular}{l|l}
0 & 0 \\
\end{tabular} & 0 & 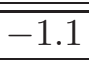 & -1.1 & -2.9 & -2.0 \\
\hline
\end{tabular}

There are no resonances within the adopted range of the analysed parameter, Fig. 4. The third natural frequency of the model is closest to the frequency of the first excitation harmonic, Fig. 4a. The ratio of the said frequencies is lowest for $\kappa=0$ and is equal to $\psi_{1,3}=f_{1, e} / f_{3}=1.16 / 0.98=$ 1.18. The frequency of the second excitation harmonic is closest to the sixth natural frequency of the model for $\kappa=1$, where $\psi_{2,6}=f_{2, e} / f_{6}=2.32 / 2.95=0.79$. Therefore, in the low-frequency range of vibrations (up to $3 \mathrm{~Hz}$ ), natural frequencies of the model are far enough from the frequencies of the first two excitation harmonics. Hence, there is no danger of system oscillations in the area close enough to resonances of the first and the second order, the appearance of which could endanger integrity of the entire structure. In the higher frequencies range, Fig. 4b, the tenth natural frequency of the model is closest to the frequency of the third excitation harmonic, where $\psi_{3,10}=f_{3, e} / f_{10}=3.48 / 3.69=0.94$ for $\kappa=1$. For the same value of the parameter $\kappa$, the ratio of the fourth frequency of excitation and the eleventh natural frequency is equal to $\psi_{4,11}=f_{4, e} / f_{11}=4.64 / 4.71=0.99$, while $\psi_{5,13}=f_{5, e} / f_{13}=5.8 / 5.92=0.98$. Although the values of coefficients $\psi_{4,11}$ and $\psi_{5,13}$ are in close proximity to 1 , the entrance into a resonant area is not observed in the model response depicted in Fig. 5 due to: (a) low energy potential of the fourth and the fifth excitation harmonics; (b) low participation of energies of structural elements, dominant in the eleventh and thirteenth modal shape, in the total energy of the system vibrations.

The curves of dependence of the maximum vertical displacements of the BWC $\left(q_{B W, V, \max }(\kappa)\right)$ and the minimum vertical displacements of the $\mathrm{CW} \mathrm{CoG}\left(q_{C W, V, \min }(\kappa)\right)$ on the parameter $\kappa$ are of a monotonically decreasing character, Fig. 6a. On the other hand, the curve of dependence of the maximum vertical displacements of the BWD CoG $\left(q_{B W D, V, \max }(\kappa)\right)$ is of a monotonically increasing nature. The curve $q_{C W, V, \min }(\kappa)$ is most sensitive to variation of the parameter $\kappa$ : for $\kappa=1$, its value is $7.0 \%$ higher than the value obtained for $\kappa=0$, Table 5 . From an engineering standpoint, the curves $q_{B W, V, \max }(\kappa)$ and $q_{B W D, V, \max }(\kappa)$ are insensitive to the parameter $\kappa$ variation, since the maximum obtained percentage differences are equal to $1.3 \%$ and $0.2 \%$, respectively, Table 5 .

Table 5. Percentage differences in the maximum values of displacements at the bounds of the interval of the parameter $\kappa$ variation

\begin{tabular}{|c|c|c|c|c|c|c|}
\hline \multirow{3}{*}{\begin{tabular}{|c} 
Percen- \\
tage \\
differ. \\
\end{tabular}} & \multicolumn{6}{|c|}{ Displacement } \\
\hline & \multicolumn{6}{|c|}{$i$} \\
\hline & $B W, V, \max$ & $B W, L, \max$ & $B W D, V, \max$ & $B W D, L, \max$ & $C W, V, \min$ & $C W, L, \min$ \\
\hline$A$ & -1.3 & 7.8 & 0.2 & 8.9 & 7.0 & -12.5 \\
\hline
\end{tabular}

The maximum values of lateral displacements of the BWC and BWD CoG as well as the minimum values of the $\mathrm{CW}$ CoG lateral displacements are by an order of magnitude lower 
than the corresponding values of vertical displacements, Fig. 6, Table 2. However, the curves $q_{B W, L, \max }(\kappa), q_{B W D, L, \max }(\kappa)$ and $q_{C W, L, \min }(\kappa)$ are considerably more sensitive to variation of the parameter $\kappa$, Table 5 . Thereby, the curve $q_{C W, L, \min }(\kappa)$ has the greatest sensitivity $(-12.5 \%)$ which can, however, be deemed insignificant because its values are negligibly small over the whole domain of variation of the parameter $\kappa$, Fig. 6b. Additionally, it is conclusive that the curve $q_{B W D, L, \max }(\kappa)$ has slightly greater sensitivity to variation of the parameter $\kappa$ than the curve $q_{B W, L, \max }(\kappa): 8.9 \%$ vs. $7.8 \%$, Table 5 .

The curves of the maximum vertical and lateral BWC and CW CoG accelerations in function of the parameter $\kappa$, Fig. 7, are of the same character. Primarily, they are monotonically decreasing down to a local minimum, Table 6 , after which they are monotonically increasing. It is important to note that the local minimums of the curves of maximum accelerations of the analysed referent points do not appear simultaneously, i.e. for the same values of the parameter $\kappa$, Fig. 7, Table 6 .

Table 6. Local minimums of the curves of the BWC and CW CoG maximum accelerations versus the parameter $\kappa$

\begin{tabular}{|l|c|c|}
\hline Curve & Parameter $\kappa$ & Local minimum value $\left[\mathrm{m} / \mathrm{s}^{2}\right]$ \\
\hline \hline$a_{B W, V, \max }(\kappa)$ & 0.85 & 0.433 \\
\hline$a_{B W, L, \max }(\kappa)$ & 0.35 & 0.114 \\
\hline$a_{C W, V, \max }(\kappa)$ & 0.45 & 0.266 \\
\hline$a_{C W, L, \max }(\kappa)$ & 0.90 & 0.007 \\
\hline
\end{tabular}

The curve of the maximum vertical accelerations of the BWD CoG has a monotonically increasing character, Fig. 7a. The curve of the maximum lateral accelerations is monotonically decreasing down to a singularity which occurs at $\kappa=0.45$, whereby the function $a_{B W D, L, \max }(\kappa)$ reaches the minimum value of $0.111 \mathrm{~m} / \mathrm{s}^{2}$, Fig. $7 \mathrm{~b}$, after which the analysed function is monotonically increasing. The said singularity is a consequence of a theoretically-possible resonant state which would appear for $\kappa=1.92$. Although it is a very far-off fourth order resonance $\left(\kappa_{\max }=1.0\right)$, its influence is apparent on the diagram of the mentioned lateral acceleration in the time domain, Fig. 8.

Lateral accelerations are significantly more sensitive than the vertical to variation of the parameter $\kappa$, Table 7 . The curve $a_{C W, L, \max }(\kappa)$ has the greatest sensitivity $(28.6 \%)$. That, however, is not significant because its values over the considered domain of the parameter $\kappa$ variation are negligibly small from the engineering standpoint, Fig. 7b. It is important to note that sensitivity of the curves $a_{B W, L, \max }(\kappa)$ and $a_{B W D, L, \max }(\kappa)$ is higher than $15 \%$, Table 7 . In terms of vertical accelerations, the curve $a_{B W D, V, \max }(\kappa)$ has the greatest sensitivity $(10.6 \%)$, while the sensitivity of the curves $a_{B W, V, \max }(\kappa)$ and $a_{C W, V, \max }(\kappa)$ is equal to $8.3 \%$ and $6.0 \%$, respectively.

Table 7. Sensitivity of the maximum acceleration of the model referent points to variation of the parameter $\kappa$

\begin{tabular}{|c|c|c|c|c|c|c|}
\hline \multirow{2}{*}{$\begin{array}{c}\text { Percen- } \\
\text { tage } \\
\text { differ. }\end{array}$} & \multicolumn{5}{|c|}{ Acceleration } \\
\cline { 2 - 7 } & $B W, V, \max$ & $B W, L, \max$ & $B W D, V, \max$ & $B W D, L, \max$ & $C W, V, \max$ & $C W, L$, max \\
\hline \hline$A$ & 8.3 & 15.8 & 10.6 & 15.3 & 6.0 & 28.6 \\
\hline$A=\left[\left(a_{i, \max }-a_{i, \min }\right) / a_{i, \min }\right] \cdot 100$
\end{tabular}

Finally, over the whole domain of the parameter $\kappa$ variation, the maximum intensities of accelerations of each of the analysed model referent points, Fig. 7, are lower than the permitted values prescribed by the Standard (DIN 22261-2, 2016), Table 8. 


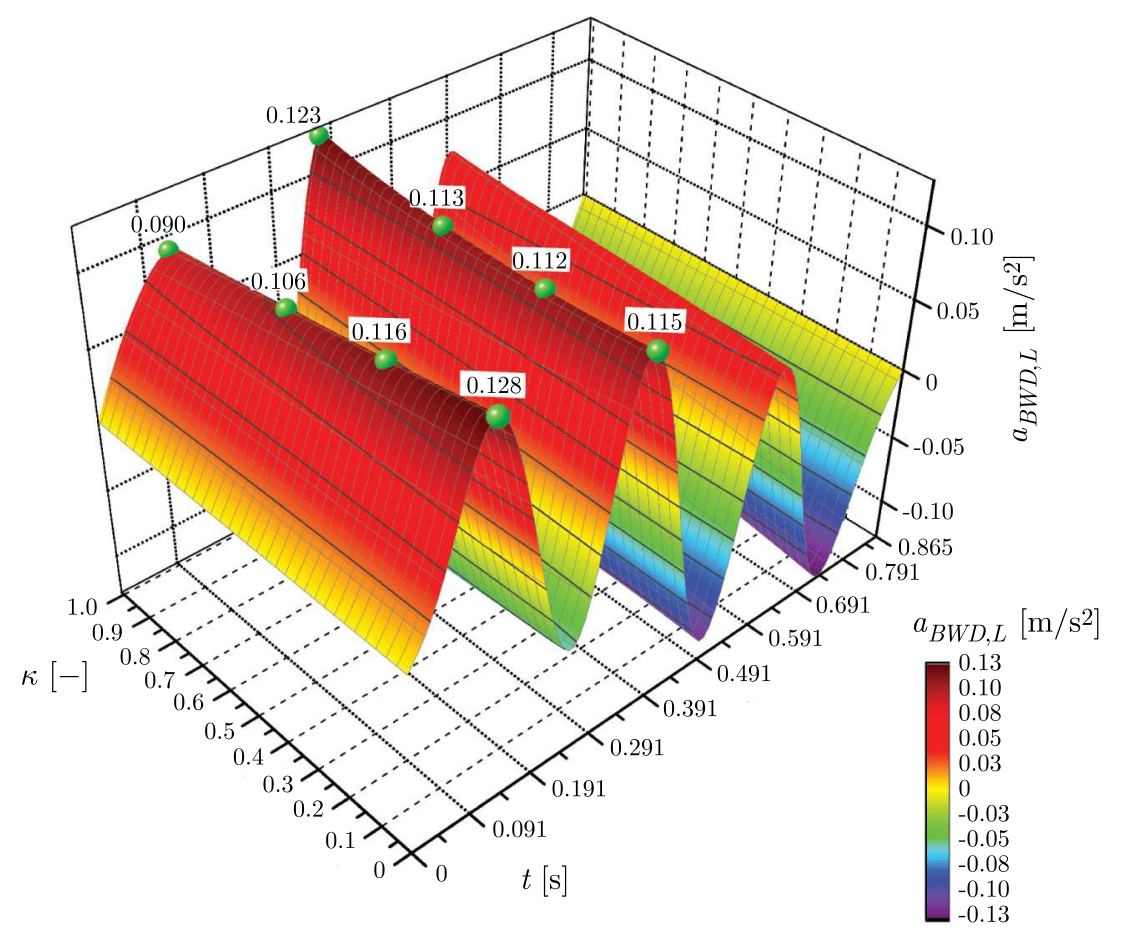

Fig. 8. Lateral acceleration of the BWD CoG reference point

Table 8. Permitted acceleration values according to the Standard (DIN 22261-2, 2016)

\begin{tabular}{|c|c|c|c|c|c|}
\hline \multicolumn{5}{|c|}{ Model referent points } \\
\hline \multicolumn{5}{|c|}{ Vertical direction: $a_{V, p e r}\left[\mathrm{~m} / \mathrm{s}^{2}\right]$} & \multicolumn{2}{|c|}{ Lateral direction: $a_{L, p e r}\left[\mathrm{~m} / \mathrm{s}^{2}\right]$} \\
\hline BW & BWD & CW & BW & BWD & CW \\
\hline \hline \multicolumn{2}{|c|}{1.0} & 0.4 & \multicolumn{2}{|c|}{0.167} & 0.333 \\
\hline
\end{tabular}

\section{Conclusion}

The goal of the research presented in this paper was to emphasise the importance of analysia of the dynamic response of bucket wheel excavator slewing superstructures in operating conditions, which is always accompanied by an increase of mass due to transport and adherence of a significant amount of the excavated soil material. The presented method of analysis of sensitivity of the bucket wheel excavator to continuous variation of the 'adhered material' mass has a significant role not only during design of new, but also during redesign, modernization and maintenance of old and obsolete machines intended for perennial exploitation under extremely harsh working conditions.

Based on the presented results of the analysis, which has been performed on a discrete spatial model of the slewing superstructure of a bucket wheel excavator with two masts, the following conclusions have been derived:

- maximum accelerations of the model referent points (bucket wheel centre, bucket wheel drive gearbox centre of gravity, counterweight centre of gravity) are significantly more sensitive to the influence of the 'adhered material' mass, compared to their maximum displacements;

- maximum lateral accelerations of the model referent points have significantly greater sensitivity to the influence of the 'adhered material' mass than their maximum vertical accelerations; 
- maximum vertical displacements of the model referent points are by an order of magnitude higher than the lateral ones, the latter of which are significantly more sensitive to variation of mass of the 'adhered material';

- over the whole domain of variation of the 'adhered material' mass, it has been observed that: (a) dependencies of the maximum/minimum values of displacements are of monotonic character; (b) dependencies of the maximum accelerations have local minimum values or are of a monotonic character. These facts point to a conclusion that, in order to assess the influence of the 'adhered material' mass in the absence of a resonance, it is sufficient to perform analysis at the lower and upper bounds of the interval (for the mass of the 'adhered material' equal to zero and for the mass of the 'adhered material' at its highest value);

- maximum intensities of accelerations of each of the referent points analysed in this paper are lower than the limiting values, prescribed by Standard DIN 22261-2, over the whole domain of variation of the 'adhered material' mass.

\section{Acknowledgment}

This work is a contribution to the Science Fund of the Republic of Serbia project PROMIS.

\section{References}

1. Arsić M., Bošnjak S., Zrnić N., Sedmak A., Gnjatović N., 2011, Bucket wheel failure caused by residual stresses in welded joints, Engineering Failure Analysis, 18, 2, 700-712

2. AS4324.1, 1995, Mobile equipment for continuous handling of bulk materials. Part 1 - General requirements for the design of steel structures, Standards Australia, Homebush

3. Bartelmus W., Zimroz R., 2009, Vibration condition monitoring of planetary gearbox under varying external load, Mechanical Systems and Signal Processing, 23, 246-257

4. Bošković S., Jovančić P., Ignjatović D., Rakićević B., Maneski T., 2015, Vibration as deciding parameter during revitalization process for replacing the bucket wheel drive, Journal of Vibroengineering, 17, 1, 24-32

5. Bošnjak S.M., Oguamanam D.C.D., ZRnić N.., 2015, The influence of constructive parameters on response of bucket wheel excavator superstructure in the out-of-resonance region, Archives of Civil and Mechanical Engineering, 15, 4, 977-985

6. Bošnjak S., Gnjatović N., 2016, The influence of geometric configuration on response of the bucket wheel excavator superstructure, FME Transactions, 44, 3, 313-323

7. Bošnjak S., Oguamanam D., ZRnić N., 2006, On the dynamic modeling of bucket wheel excavators, FME Transactions, 34, 4, 221-226

8. Bošnjak S., Petković Z., Zrnić N., Simić G., Simonović A., 2009, Cracks, repair and reconstruction of bucket wheel excavator slewing platform, Engineering Failure Analysis, 16, 5, 1631-1642

9. BoŠNJAK S., ZRnić N., 2012, Dynamics, failures, redesigning and environmentally friendly technologies in surface mining systems, Archives of Civil and Mechanical Engineering, 12, 3, 348-359

10. Brkić A., Maneski T., Ignjatović D., Jovančić P., Spasojević Brkić V., 2014, Diagnostics of bucket wheel excavator discharge boom dynamic performance and its reconstruction, Maintenance and Reliability, 16, 2, 188-197

11. Brusa E., Morsut S., Bosso N., 2014, Dynamic behaviour and prevention of the damage of material of the massive hammer of the scrap shredding machine, Meccanica, 49, 3, 575-586

12. Cireş I., NAni V. M., 2016, Stability control for a huge excavator for surface excavation, Applied Mathematical Modelling, 40, 1, 388-397 
13. DIN 22261-2, 2016, Excavators, Stackers and Auxiliary Equipment in Brown Coal Open Cut Mines. Part 2 - Calculation Principals, German Institute for Standardization, Berlin

14. Gnjatović N., 2016, Influence of constructional parameters and parameters of excitation on response of the bucket wheel excavator with two masts in the out-of-resonance region (in Serbian), Ph.D. Thesis, University of Belgrade, Faculty of Mechanical Engineering, Belgrade

15. Gottvald J., 2010, The calculation and measurement of the natural frequencies of the bucket wheel excavator SchRs 1320/4x30, Transport, 25, 3, 269-277

16. Gottvald J., 2012, Analysis of vibrations of bucket wheel excavator SchRs 1320 during mining process, FME Transactions, 40, 4, 165-170

17. Huss W., 2014, An application of statistical tools in the identification of the transient vibrations of bucket-wheel excavators under random loads, [In:] Advances in Condition Monitoring of Machinery in Non-Stationary Operations, G. Dalpiaz et al. (Eds.), Springer-Verlag, Berlin Heidelberg, 545-555

18. Karray M., Feki N., Khabou M.T., ChaAri F., Haddar M., 2017, Modal analysis of gearbox transmission system in bucket wheel excavator, Journal of Theoretical and Applied Mechanics, 55, 1, 253-264

19. Ognjanović M., Benur M., 2011, Experimental research for robust design of power transmission components, Meccanica, 46, 699-710

20. Ognjanović M., Ristić M., Živković P., 2014, Reliability for design of planetary gear drive units, Meccanica, 49, 829-841

21. Pietrusiak D., 2017, Evaluation of large-scale load-carrying structures of machines with the application of the dynamic effects factor, Maintenance and Reliability, 19, 4, 542-551

22. Pietrusiak. D, Smolnicki. T, Stańco M., 2017, The influence of superstructure vibrations on operational loads in the undercarriage of bulk material handling machine, Archives of Civil and Mechanical Engineering, 17, 855-862

23. Rusiński E., Czmochowski J., Moczko P., Kowalczyk M., Pietrusiak D., PrzybyŁek G., Smolnicki T., Stańco M., 2015, Assessment of the Technical Condition of Mining Machines (in Polish), Oficyna Wydawnicza Politechniki Wrocławskiej, Wroclaw

24. Rusiński E., Czmochowski J., Moczko P., Pietrusiak D., 2017, Surface Mining Machines: Problems of Maintenance and Modernization, Springer, Cham

25. Rusiński E., Dragan S., Moczko P., Pietrusiak D., 2012, Implementation of experimental method of determining modal characteristics of surface mining machinery in the modernization of the excavating unit, Archives of Civil and Mechanical Engineering, 12, 4, 471-476

26. Schlecht B., 2014, Investigation and Optimization of the Dynamic Behaviour of the Bucket Wheel Drives (in German), Final report of the research project 16575 BR funded by the Federal Ministry for Economic Affairs and Energy of Germany

27. Schneider F., 2007, Bucket wheel excavator system EPS, SchRs 1600/3*25, Load assumptions according to DIN 22261-2, ThyssenKrupp Fördertechnik, Essen

28. Volkov D. P., Cherkasov V.A., 1969, Dynamics and Strength of Multi-Bucket Excavators and Stackers (in Russian), Mašinostroenie, Moscow 